TP Periodica Polytechnica Chemical Engineering

62(2), pp. 144-149, 2018

https://doi.org/10.3311/PPch.10465

Creative Commons Attribution (i)

RESEARCH ARTICLE

\section{A Tool for a Spacer Material and Ion-exchange Membrane Compatibility Evaluation for Electrodialysis Module Design}

\author{
Jakub Fehér $^{1 *}$, Kateřina Keslerová ${ }^{2}$, Michal Amrich ${ }^{1}$
}

Received 03 January 2017; accepted after revision 21 April 2017

\begin{abstract}
Electrodialysis is a widely used separation process for wastewater treatment, concentration of valuable products or production of organic acids. However, unwanted phenomena can occur during the operation of electrodialysis stacks such as internal leakage and/or external leak. In this study, a new simple tool is presented for testing materials suitable for use as spacers used in ED. This cell for testing leaks simulates ED stack and therefore allowing external leaks to be tested. Regarding tests results suitable materials for an ED scale-up can be chosen. Tests were done for three different pressures (1.5, 2 and 2.5 bar) and three different temperatures (25, 40 and $\left.60{ }^{\circ} \mathrm{C}\right)$. To maintain the same conditions, the test cell was tightened by defined force in the range of 850 to $870 \mathrm{~N}$. In the testing stack different combinations of membrane, and spacers were tested. It was found that with increasing temperature leaks decrease. Parameters that influence external leaks most are surface roughness, texture a hardness of ion-exchange membrane and spacer material.
\end{abstract}

\section{Keywords}

electrodialysis, external leaks, leakage, spacer

\footnotetext{
${ }^{1}$ Membrane Processes Department,

MemBrain s.r.o, Stráž pod Ralskem, Czech Republic

${ }^{2}$ Faculty of Mechatronics, Informatics and Interdisciplinary Studies,

Technical University of Liberec, Liberec, Czech Republic

*Corresponding author, e-mail: jakub.feher@membrain.cz
}

\section{Introduction}

Electrodialysis is an electrochemical membrane separation process which uses ion-exchange membranes to separate ions from solutions. The driving force of this process is the electric potential difference. An electrodialysis (ED) module consists of a membrane stack between two electrodes and end plates. The stack itself is composed of alternating cation-exchange and anion-exchange membranes separated by spacers. Spacers create working space between the ion-exchange membranes and provide proper fluid flow and hydrodynamics. Ions are accumulated in concentrate chambers and removed from dilate chambers.

In recent years, several ED applications have been developed and introduced in the industry. Mainly in the food, drug and chemical process industries, waste water treatment or high quality water production $[1,2]$. In recent years, new ED configurations have been introduced, particularly ED with bipolar membranes. This technology has been getting more and more attention especially in the production of organic acids, such as citric acid [3], acetic acid [4] and formic acid [5], but also for the production of amino acids, for example phenylglycine [5]. Bipolar membrane electrodialysis has been used in the recovery of acids and bases and thus follows today trend in being more and more environmentally conscious.

However, unwanted phenomena can occur in electrodialysis modules, such as high pressure losses, internal leakage or external leaks [6]. Internal leakages occur between diluate and concentrate stream. The main cause of such phenomena is the deformation of IM membranes into flow distributors, or a pressure difference between the concentrate and diluate streams [7]. External leaks refer to solution leaks from the ED stack, and are a consequence of pressure inside the stack, and the ability of spacers and membranes to seal the stack tightened by given force. Each electrodialysis stack has a maximum inlet pressure at which ED operates. If the maximum pressure inside an ED stack is exceeded, external leaks occur [8]. If these negative effects develop, the electrodialysis process become less effective and thus inadequate for industrial use. When a valuable product is being produced by ED, external leaks result in loss of this product. Moreover, external leaks can be a problem for 
operation of the module in the technology, and can be a safety hazard for operators, for example when $\mathrm{H}_{2} \mathrm{SO}_{4}$ is produced by bipolar ED. Therefore, the spacers used in electrodialysis modules need to be designed with a focus on eligible hydrodynamics, low external leaks, and as low as possible leakage between compartments. To prevent leaks from the inside to the outside of the stack, spacer material should be soft enough, but should also be hard and stable. Material should withstand different chemicals and $\mathrm{pH}$ and avoid dimensional changes over time. Nowadays materials used include polyethylene copolymers, polypropylene copolymers, EVA copolymers and few others [8-10].

In this work, an experimental device for testing the compatibility of ion-exchange membranes and spacer materials is presented. With regard to the results from this simple device appropriate spacer materials before ED scale-up can be chosen for any given type of ion-exchange membrane.

Different spacer materials were tested with three different heterogeneous ion-exchange membranes manufactured by Mega a.s. (Czech republic, Stráž pod Ralskem) and MemBrain s.r.o (Czech republic, Stráž pod Ralskem) with different pressures and temperatures.

\section{Materials and methods}

\subsection{Ion-exchange membranes}

In this work, leaks for three different ion-exchange membranes were studied. Ralex ${ }^{\circledR}$ IM-PES, Ralex ${ }^{\circledR}$ IM-PP (both manufactured by Mega a.s., Czech Republic) and innovative temperature resistant IM Ralex ${ }^{\circledR}$ IM-PES TR (MemBrain s.r.o, Czech Republic). All three types of IM are heterogeneous and have reinforcing fabric. The differences between ion-exchange membranes lie in the material used for reinforcing fabric and also in the binding polymer. In Ralex ${ }^{\circledR}$ IM-PES and IM-PES TR the fabric made out of polyester is used while in Ralex ${ }^{\circledR}$ IM-PP polypropylene fabric is employed. The binding polymer is a polyethylene copolymer, and is the same for Ralex ${ }^{\circledR}$ IM-PES and IM-PP, however Ralex ${ }^{\circledR}$ IM-PES TR is made out of a polyethylene copolymer, which is resistant to higher temperatures.

To be able to simulate a real electrodialysis stack, ion-exchange membranes were firstly put in demi water to swell for three days. After swelling, the IM were cut in annular rings with an area of $50 \mathrm{~cm}^{2}$. This preparation was the same for cation-exchange and anion exchange membranes, for all the types of IM described above.

\subsection{Spacers}

In an electrodialysis stack, spacers are used between two ion-exchange membranes to create space for fluid flow. In this study, seven different materials were used for spacers.

The materials for spacers were prepared in MemBrain s.r.o. from polymer resins. HDPE material is high density polyethylene. For other materials, their manufacturers claim that these materials are random polypropylene copolymers. Nonetheless, the mass fraction of PE of PP is not further specified. FT-IR spectra measurement, using Nicolet ${ }^{\mathrm{TM}}$ iS $^{\mathrm{TM}} 50 \mathrm{FT} /$ IR Spectrometer (Thermo Fisher Scientific, USA), showed that these materials are pure isotactic polypropylenes (for example in Fig. 1 Lumicene ${ }^{\circledR}$ MR30MC2 spectra in comparison with pure isotactic polypropylene spectra is shown). Therefore, in Table 1 these materials are referred as polypropylene polymers.

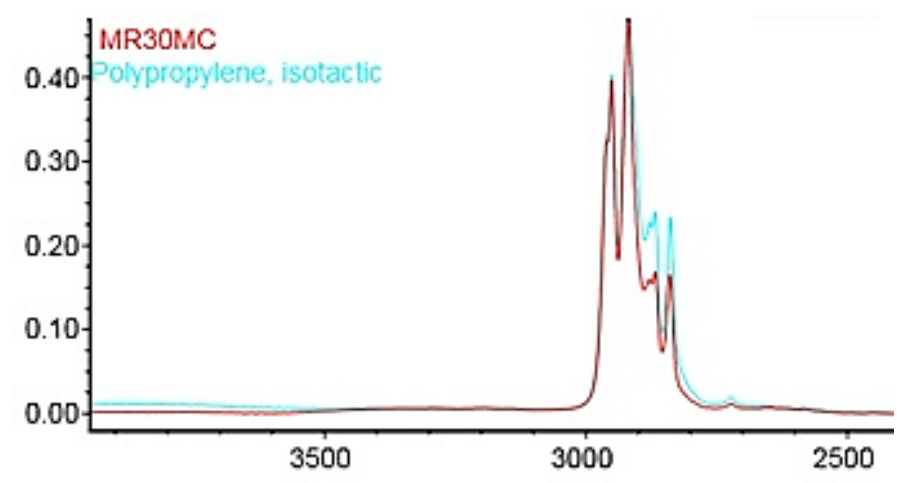

Fig. 1 FTIR spectra for Lumicene ${ }^{\circledR}$ MR30MC2

The thickness of all spacers was $0.8 \mathrm{~mm}$. The materials are characterized in Table 1. The roughness of the material surface is characterized via Ra and Rz. Ra is the arithmetic mean of the magnitude of the deviation of the profile from the mean line. Rz is the highest peak to valley, usually analysed as mean over a five measurements. Hardness is expressed in Shore D degrees. Hardness was measured with a durometer equipped with a steel rod with $30^{\circ}$ conical point, 0.1 tip radius and $2.5 \mathrm{~mm}$ length. The applied force was $44.5 \mathrm{~N}$.

Table 1 Characterization of used spacer materials

\begin{tabular}{|c|c|c|c|c|}
\hline Name of material & $\begin{array}{l}\text { Material } \\
\text { type }\end{array}$ & $\mathrm{R}_{\mathrm{a}}[\mu \mathrm{m}]$ & $\begin{array}{l}\mathrm{Rz} \\
{[\mu \mathrm{m}]}\end{array}$ & Shore D \\
\hline HDPE HPA 020 & $\mathrm{PE}$ & 0.21 & 1.59 & 41.67 \\
\hline Versify $^{\mathrm{TM}} 2000$ & PP & 3.15 & 15.93 & 47.67 \\
\hline Tipplen R660 & PP & 0.20 & 1.06 & 60.58 \\
\hline Tipplen R659 & PP & 0.20 & 1.26 & 62.17 \\
\hline Lumicene ${ }^{\circledR}$ MR30MC2 & PP & 0.19 & 1.29 & 60.92 \\
\hline Lumicene ${ }^{\circledR}$ MR10MX0 & PP & 0.19 & 1.39 & 62.08 \\
\hline Braskem DR7051.01 & PP & 0.21 & 1.40 & 65.58 \\
\hline
\end{tabular}

The manufacturers of the polymer resins are ExxonMobil ${ }^{\mathrm{TM}}$, USA (HDPE HPA 020); The Dow Chemical Company, USA (Versify ${ }^{\mathrm{TM}}$ 2000); TVK Plc., Hungary (Tipplen R660 and Tipplen R659); Total Refining\&Chemicals, Belgium (Lumicene $^{\circledR}$ MR30MC2 and MR10MX0); Braskem, USA (Braskem DR7051.01). 


\subsection{Cell for seal-testing and membrane stack}

Construction of the cell for seal-testing (hereafter CST) is illustrated in Fig. 2. The membrane stack consisted of alternating cation-exchange and anion-exchange membranes. Spacers were placed between anion and cation exchange membranes. The stack consisted of 30 membrane pairs and was placed in a cell for testing leaks. Between the first membrane and CST plate, a silicon rubber gasket was placed to prevent leaks from this area (the same gasket was applied between the last membrane and CST plate).

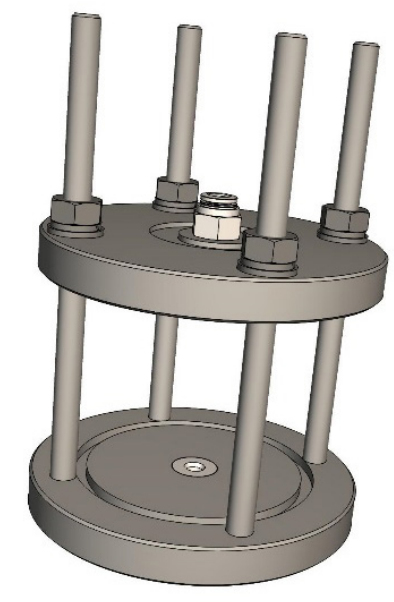

Fig. 2 Illustration of cell for seal testing

In order to ensure the same conditions for all measurements, CST had been tightened by force, in a range $850-870 \mathrm{~N}$, using the tearing machine Tinius Olsen H5KT, equipped with a 5000 $\mathrm{N}$ sensor. First the CST was compressed by force slightly exceeding $1000 \mathrm{~N}$. After one minute, the compression by a force slightly exceeding $1000 \mathrm{~N}$ was repeated, and then after about 10 minutes of relaxing the stack, the force stabilizes in given range $850-870 \mathrm{~N}$.

\subsection{Leaks test}

Equipment for measuring leaks is shown on Fig. 3. The stack in a CST is located at the top part of the equipment.

Water from a tank was pumped to the stack and after passing through the stack in CST water returned to the tank. The cryostat ensured constant water temperature. Leaks were measured for three different temperatures $\left(25^{\circ} \mathrm{C}, 40^{\circ} \mathrm{C}\right.$ and $\left.60^{\circ} \mathrm{C}\right)$ and three different pressures (1.5 bar, 2 bar and 2.5 bar).

Pressure 2.5 bar is the recommended maximum pressure at which industrial modules of Mega a.s. operate [6].

Firstly demi water at the desired temperature circulated in the equipment at a volume flow of $300 \mathrm{~L} / \mathrm{h}$, for $15 \mathrm{~min}$. After that, the valve on the outflow from the CST was closed, and via a membrane valve and bypass, the desired pressure was set. Water leaks were collected in a beaker on which the CST was placed horizontally. For each pressure and temperature, the test was repeated three times.

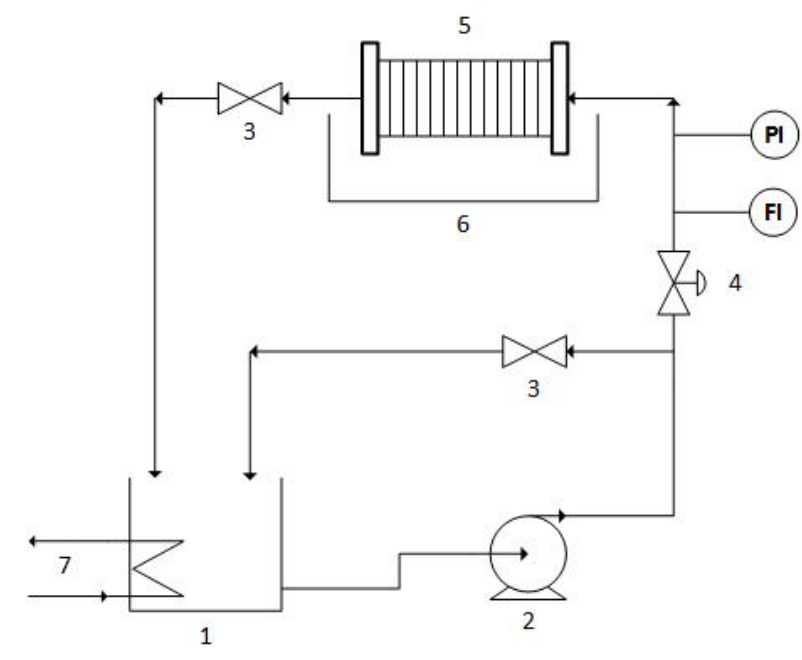

Fig. 3 Scheme of equipment for leaks testing. 1) Tank, 2) Pump, 3) Valve, 4) Membrane valve, 5) CST, 6) Beaker, 7) Cooling/heating provided by cryostat, PI - manometer, FI - rotameter

The final volume of the leaks was determined as the average from the three tests and divided by the number of membrane pairs. Results are presented in $\mathrm{mL} \cdot \mathrm{h}^{-1}$. pair $^{-1}$.

\section{Results and discussion}

Results are shown in Fig. 4, Fig. 5 and Fig. 6. The dependence between the temperature and the volume of leaks has been found. It has been shown that the higher the water temperature, the lower the leaks. At $60{ }^{\circ} \mathrm{C}$, leaks decreased often to zero, which led to the drying out of the outer edge of the ion-exchange membranes. The physical characteristics of spacer materials are determined by temperature, including hardness and resilience. It has been proven that hardness decreases with an increase in temperature $[11,12]$. Due to decreased hardness, increased compressibility of materials, and material thermal expansion, the stack became better sealed. Subsequently the only mechanism by which water reaches edge is diffusion. Veerman et al. presented diffusion coefficients of water for QianQiu heterogeneous ion-exchange membranes (Hangzhou QianQiu Industry Co., China). The diffusion coefficient of water in these membranes was $3.910^{-5} \mathrm{~cm}^{2} \cdot \mathrm{s}^{-1}$.[13] Although the water diffusion coefficient will not be the same for the IM membranes used in this paper, it can be expected that the diffusion coefficient of IM PES, IM PP and IM PES TR membranes is somewhat similar to coefficient for QianQiu membranes. Membranes used in this study and QianQiu membranes are heterogeneous, and have similar thickness and water content when in their swollen state.

Data sheets of QianQiu membranes and Ralex ${ }^{\circledR}$ membranes can be found at the websites $[14,15]$. Regarding to Vermaan et al. results, it is assumed that the diffusion in IM membranes used in this study is rather slow. Therefore, evaporation rate at $60^{\circ} \mathrm{C}$ was faster than diffusion itself and drying out occurred. Consequently the volume of leaks was null, or significantly lower, than in tests for $25^{\circ} \mathrm{C}$ and $40{ }^{\circ} \mathrm{C}$. 


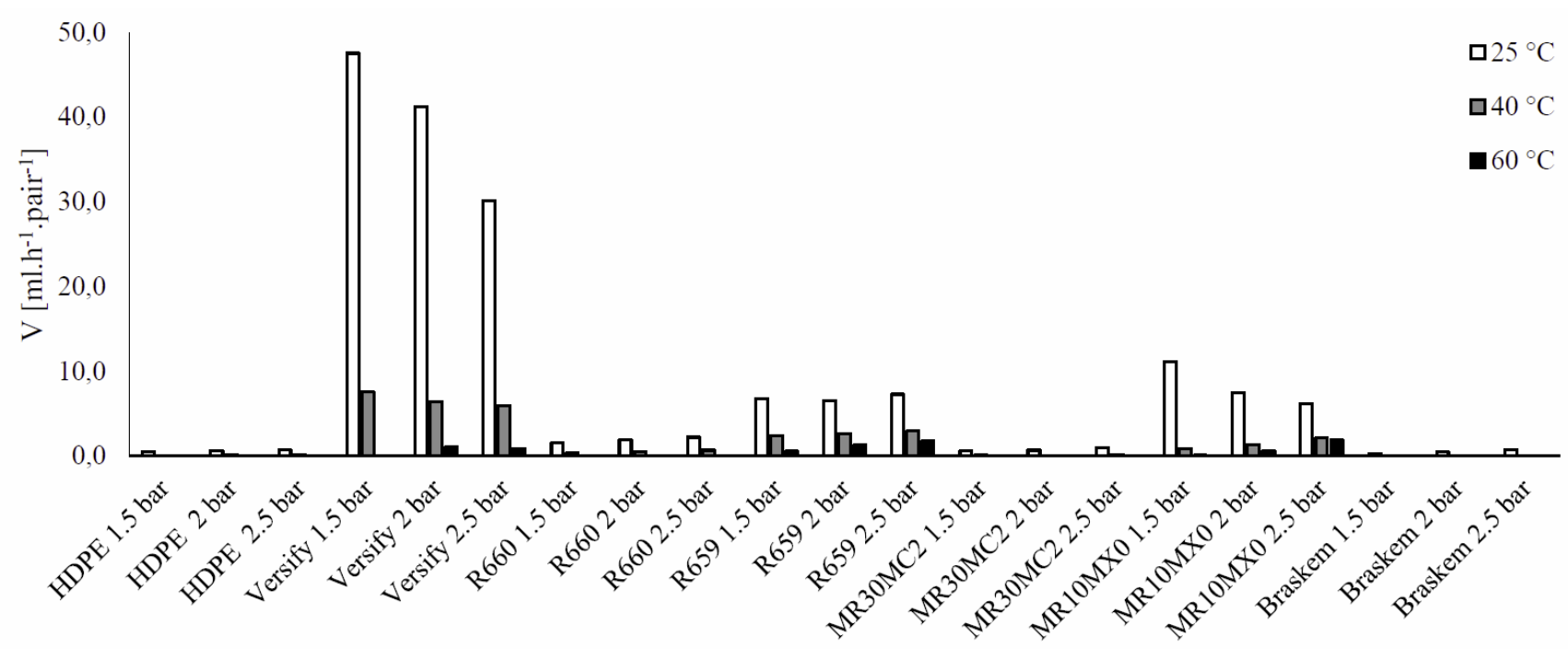

Fig. 4 Tests results for stack with IM PES membrane

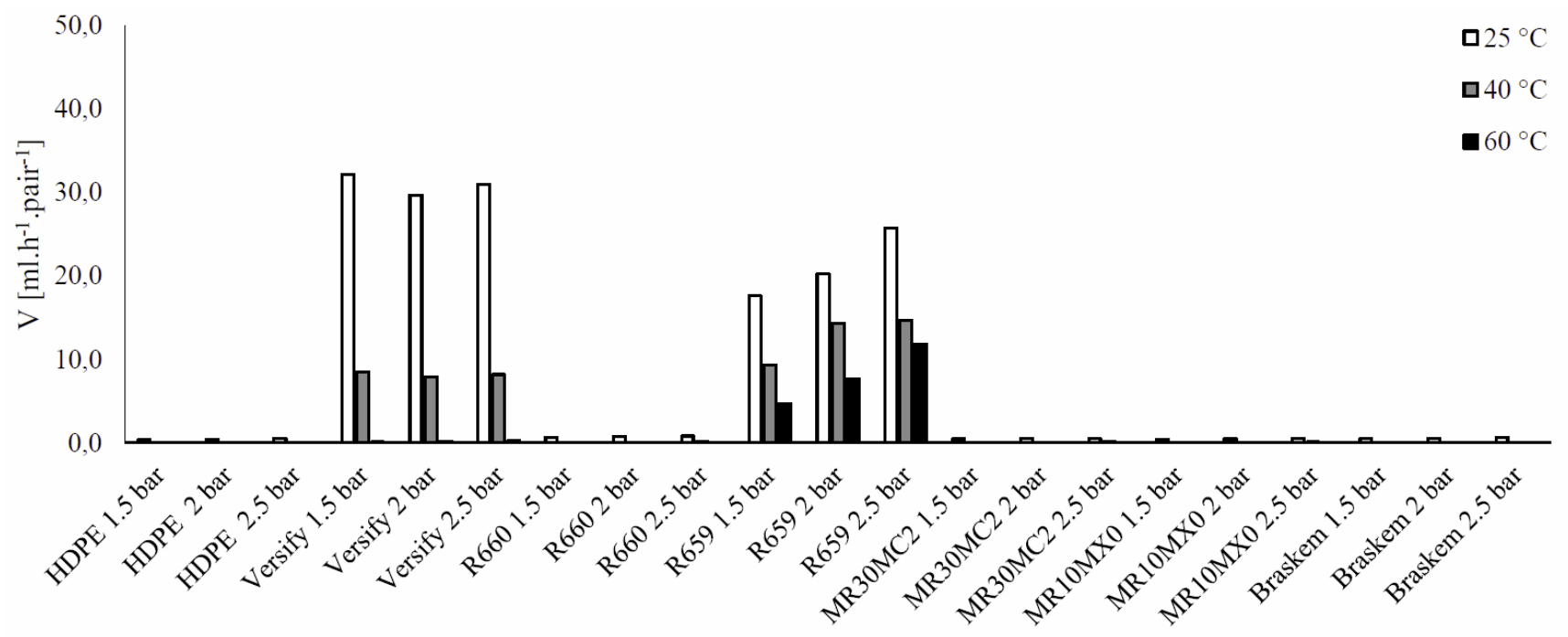

Fig. 5 Tests results for stack with IM PP membrane



Fig. 6 Tests results for stack with IM PES TR membrane 
Despite expectations, the dependence between the pressure and the volume of leaks is unclear. In most cases, the volume of leaks increased with increased pressure. Nevertheless, in some cases the trend was the opposite, like in the stack with IM PES membranes and spacers from Versify (see Fig. 4). Low sealing ability of Versify 2000 is caused by the high roughness of the surface of the spacer; the value is about 16 times higher than for other spacers as is shown in Table 1.

Surface texture has a direct impact on the sealing ability of material, and roughness $\mathrm{Ra}$ has the dominant influence [12, 16]. Interesting fact is that, at higher temperatures with spacer Versify 2000 leaks for IM-PES TR membrane were lower than for other tested membranes. Also, the volume of leaks from the stack with Versify and IM PES TR membranes is not the biggest, as it was in the stack with IM PES or IM PP membranes with Versify 2000. The cause of such behaviour is that IM PES TR is more compatible with Versify material. Although, the Ra is a good parameter for the characterization of material, it has its limitations. $\mathrm{Ra}$ is arithmetic average value of the profile, but does not tell anything about surface texture, which means that various surfaces can have the same Ra value. The illustration of such scenario is shown in Fig. 7.

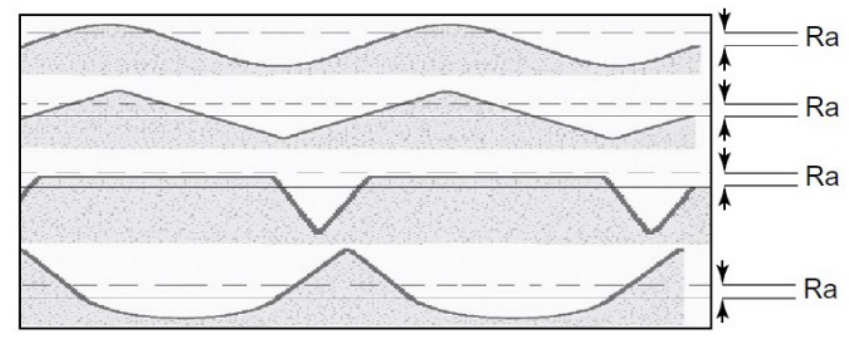

Fig. $7 \mathrm{Ra}$ is independent of the surface-texture profile and machining operation. Three different surface profiles have the same Ra value [16].

Moreover, the leak is influenced by both materials - spacers and ion-exchange membrane. To eliminate leaks from the seal requires a consideration of both materials together, so that it is ensured that the spacer materials fill the surface texture of the counter-face [16], in our case of the IM membrane. Therefore, for IM PES TR membrane, the Versify spacer material is more suitable than some of the other materials (for example Tipplen R659), even with a lower Ra parameter.

Another issue is that spacer materials from the same manufacturer, with the same Ra parameter (Tipplen R660 vs. Tipplen R659; Lumicene ${ }^{\circledR}$ MR30MC2 vs. Lumicene ${ }^{\circledR}$ MR30MX0) had different results for the same ion-exchange membranes. These materials differ in their height parameter Rz parameter and hardness (Table 1). For these four cases is observed that with higher Shore D value and $\mathrm{Rz}$, the value volume of leaks increases.

Low leaks from the stack with a combination Barskem material spacers with all of the IM membranes, despite the highest hardness of their material, can be explained by surface texture.
The profile of surface is quite compatible with the surface texture of the membranes. On the contrary low leaks from the stack with HDPE spacers are a result of the low hardness of the material and therefore in its better compressibility [12].

IM PES TR membranes had the highest volume of leaks with every spacer material compared to IM PES or IM PP. On the contrary, IM PP had the lowest volume of leaks for almost every combination, in comparison with other given membranes. To explain this result, a Shore D hardness test for swollen ion-exchange membranes was performed (for a method see chapter 2.2). Results are listed in Table 2. Both, anion-exchange and cation-exchange TR membranes, had the greatest value of Shore D degrees, while IM PP membranes had the lowest value of hardness. With reference to these results, it can be stated that the hardness of membranes influence the system significantly. The firmer the membrane, the harder it is to seal the stack appropriately.

Table 2 Hardness of IM membranes

\begin{tabular}{lll}
\hline Membrane type & Reinforcing fabric & Shore D \\
\hline CM PES & PES & 31.35 \\
AM PES & PES & 33.05 \\
CM PP & PP & 29.65 \\
AM PP & PP & 32.70 \\
CM PES TR & PES & 33.75 \\
AM PES TR & PES & 38.80 \\
\hline
\end{tabular}

Interestingly, for each type of IM membrane various spacer materials are suitable. For IM PES membranes the most suitable choices are HDPE and Braskem. For IM PP most of the materials are suitable, except Versify 2000 and Tipplen R659. Clearly for IM PES TR membranes most of the tested materials are not suitable, which is caused mostly by the toughness of temperature resistant membranes. The best choice among these materials is the Tipplen R660.

\section{Conclusions}

The aim of this work was to study the influence of various combinations of spacer materials with ion-exchange membranes on the external leaks from the ED stack and regarding the results chose the suitable material for each type of the ion-exchange membrane. Experimental leak tests were carried out for the three types of ion-exchange membranes and seven types of spacer materials. The measurements has been carried out on a special testing device, "CST"(described in chapter 2.3), which has been constructed to simulate the conditions in the electrodialysis stack. Measurements were taken for three pressures and three different temperatures of water pumped into the stack.

The dependence between the volume of leaks and the temperature of the water has been found. It has been shown that the higher the water temperature, the lower the leaks. In general, 
the dependence between the volume of leaks and pressure has not been found, though in the most measurements, with increased pressure, the volume of leaks increased as well.

Spacer material properties such as surface roughness, texture and hardness influence the ability to seal the stack properly. However, mechanical properties and surface texture of the ion/exchange membranes have significant impact on external leaks as well. Due to this, for each membrane a different material is suitable.

Authors believe that this simple and cheap method can help evaluate the fitness of materials for given IM membrane type. Regarding material properties and tests on CST, optimal combination of membrane and spacer material can be found before the scale-up of ED stack into industrial size.

\section{List of abbreviations}

$\begin{array}{ll}\text { ED } & \text { electrodialysis } \\ \text { IM } & \text { ion-exchange membrane } \\ \text { PES } & \text { polyester } \\ \text { PP } & \text { polypropylene } \\ \text { PE } & \text { polyethylene } \\ \text { TR } & \text { temperature resistant } \\ \text { EVA } & \text { ethylene-vinyl acetate }\end{array}$

\section{Acknowledgement}

The work was carried out within the framework of the project No. LO1418 "Progressive development of Membrane Innovation Centre" supported by the program NPU I Ministry of Education Youth and Sports of the Czech Republic, using the infrastructure Membrane Innovation Centre.

\section{References}

[1] Garcia-Vasquez, W., Ghalloussi, R., Dammak, L., Larchet, C., Nikonenko, V., Grande, D. "Structure and properties of heterogeneous and homogeneous ion-exchange membranes subjected to ageing in sodium hypochlorite." Journal of Membrane Science. 452, pp. 104-116. 2014. https://doi.org/10.1016/j.memsci.2013.10.035

[2] Tado K., Sakai, F., Sano, Y., Nakayama, A. "An analysis on ion transport process in electrodialysis desalination." Desalination. 378, pp. 60-66. 2016. https://doi.org/10.1016/j.desal.2015.10.001

[3] Haiping, L., Cheng, X., Liu, G., Zhou, Y., Lu, Y., Zhang, R., Li, X., Teng, W. "Citric acid production using a biological electrodialysis with bipolar membrane." Journal of Membrane Science. 523, pp. 122-128. 2017. https://doi.org/10.1016/j.memsci.2016.09.063

[4] Xu, Z., Li, C., Wang, Y., Luo, J., Xu, T. "Recovery of acetic acid from simulated acetaldehyde wastewaters: Bipolar membrane electrodialysis processes and membrane selection." Journal of Membrane Science. 379, pp. 184-190. 2011. https://doi.org/10.1016/j.memsci.2011.05.059

[5] Yongming, Z., Yan, H., Wang, X., Xu, T. "A closed loop production of water insoluble organic acid using bipolar membranes electrodialysis (BMED)." Journal of Membrane Science. 520, pp. 345-353. 2016. https://doi.org/10.1016/j.memsci.2016.08.011
[6] Novák, L. "Elektromembránové procesy." (Electromembrane processes.) Vysoká škola chemicko-technologická v Praze, Praha, Czech Republic. 2014. (in Czech)

[7] Strathmann, H. "Ion-exchange membrane separation processes." Membrane science and technology series. Vol. 9, $1^{\text {st }}$ edition, Elsevier B.V., Amsterdam, Netherlands, 2004.

[8] Tanaka, Y. "Ion Exchange Membranes Fundamentals and Applications." $2^{\text {nd }}$ edition, Elsevier B.V., Amsterdam, Netherlands, 2015.

[9] Tarleton, S. "Progress in filtration and separation." Elsevier Ltd., London, United Kingdom. 2015.

[10] Nunes Pereira, S., Peinemann, K. "Membrane Technology in the Chemical Industry." $2^{\text {nd }}$ edition, Wiley, Weinheim, Germany, 2006.

[11] Sahin, S., Yayla, P. "Effects of testing parameters on the mechanical properties of polypropylene random copolymer." Polymer Testing. 24, pp. 613-619. 2005. https://doi.org/10.1016/j.polymertesting.2005.03.002

[12] Shackelford, J. "Introduction to Materials Science for Engineers, Global Edition." Pearson Education Limited, New York City, USA, 2015.

[13] Veerman, J., de Jong, R. M., Saakes, M., Metz, S. J., Harmsen, G. J. "Reverse electrodialysis: Comparison of six commercial membrane pairs on the thermodynamic efficiency and power density." Journal of Membrane Science. 343, pp. 7-15. 2009. https://doi.org/10.1016/j.memsci.2009.05.047

[14] Ralex ${ }^{\circledR}$ Data sheets, Mega a.s., Stráž pod Ralskem, Czech republic. (in Czech) URL: http://ralex.eu/Membrany/Portfolio.aspx?id=1

[15] QianQiu PE Heterogeneous Ion-exchange membrane, Data sheet, Hangzhou QianQiu Industry Co., Linan City China. URL: http://www.linanwindow.com/qianqiu/membeng.htm

[16] Flitney, R. "Seals and sealing handbook." Butterworth-Heinemann, Waltham, USA, 2014 